\title{
Determinantes de Adesão ao Índice de Sustentabilidade Empresarial da BM\&FBOVESPA e sua Relação com o Valor da Empresa
}

(Determinants of the Inclusion in the BM\&FBOVESPA Corporate

Sustainability Index and its Relationship with Firm Value)

\author{
Lélis Pedro Andrade* \\ Aureliano Angel Bressan** \\ Robert Aldo Iquiapaza*** \\ Bruno César de Melo Moreira*****
}

\section{Resumo}

Este artigo foi realizado com o objetivo de identificar variáveis que se apresentam como determinantes de adesão de empresas brasileiras ao Índice de Sustentabilidade Empresarial (ISE) da BM\&FBOVESPA, e se tal adesão apresenta relação com o valor de mercado das empresas. Foram coletados dados anuais das empresas, no período de 2006 a 2011. A metodologia compreendeu a aplicação de diferentes métodos, tais como a análise de regressões do tipo logit e de dados em painel. Os resultados obtidos demonstraram que as empresas que têm maior tamanho, maior rentabilidade e são de setores considerados de alto impacto ambiental, possuem maior probabilidade de aderirem ao ISE. Quando se analisou se a adesão ao ISE possui relação com as métricas de valor da empresa, os resultados não rejeitaram a hipótese de relação positiva, porém, foram encontrados indícios de relação negativa no período pós-crise financeira de 2008.

Submetido em 30 de outubro de 2012. Reformulado em 30 de março de 2013. Aceito em 17 de maio de 2013. Publicado on-line em 1 de julho de 2013. O artigo foi avaliado segundo o processo de duplo anonimato além de ser avaliado pelo editor. Editor responsável: Ricardo P. C. Leal

*Universidade Federal de Minas Gerais - UFMG, Minas Gerais, Brasil. E-mail: lelis.pedro@ifmg.edu.br

**Universidade Federal de Minas Gerais - UFMG, Minas Gerais, Brasil. E-mail: bressan@face.ufmg.br

***Universidade Federal de Minas Gerais - UFMG, Minas Gerais, Brasil. E-mail: riquiapaza@gmail.com

****Instituto Federal de Minas Gerais - IFMG, Minas Gerais Brasil.

E-mail: bruno.melo@ifmg.edu.br

\footnotetext{
Rev. Bras. Finanças (Online), Rio de Janeiro, Vol. 11, No. 2, June 2013, pp. 181-213 ISSN 1679-0731, ISSN online 1984-5146

(C)2013 Sociedade Brasileira de Finanças, under a Creative Commons Attribution 3.0 license -

http://creativecommons . org/licenses/by/3.0
} 
Palavras-chave: Índice de Sustentabilidade Empresarial (ISE); valor de mercado da empresa; crise financeira.

Códigos JEL: G3; C33; C35.

\begin{abstract}
The aim of this study was to identify the variables that influence the firms inclusion in the BM\&FBOVESPA Corporate Sustainability Index (CSI), and if such membership is correlated with the firm market value in the Brazilian market. We collected annual data of firms for the period 2006 to 2011. The methodology included the use of regression analysis methods such as logit and panel data models. The results showed that companies that have joined the ISE have characteristics distinct from those who did not opt for membership. Firms with larger size, higher profitability and sectors considered of high environmental impact are more likely to be classified in the ISE. When examined whether inclusion in the CSI has relation with firm value, the results did not reject the hypothesis of positive relationship, however, we found evidence of a negative relationship in the post-2008 crisis period.
\end{abstract}

Keywords: Corporate Sustainability Index (CSI); firm value; financial crisis.

\title{
1. Introdução
}

A sustentabilidade empresarial (SE) vem sendo considerada um investimento ou uma estratégia de negócio que compreende a adoção de melhores práticas de gestão que vão ao encontro das necessidades atuais e futuras dos stakeholders.

Os investimentos em SE vêm sendo cada vez mais debatidos entre acadêmicos, administradores e demais interessados na empresa, originando questões que ainda não foram respondidas de forma conclusiva. A este respeito, cabe destacar a existência de um conflito de argumentos entre os benefícios alcançados com os investimentos em sustentabilidade empresarial. Por um lado, existe o argumento de que a atividade de negócios tem uma dimensão ética, que vai além da dimensão econômica e da legal. Porém, conforme destacaram Machado Filho \& Zylbersztajn (2004), não existe consenso sobre a natureza desta dimensão e sobre quem deve se responsabilizar por ela. 
Assim, um grupo de acadêmicos defende a teoria dos shareholders, que argumenta que as decisões dos administradores devem estar voltadas unicamente para incrementar a riqueza dos proprietários das empresas, enquanto outro grupo defende, com base em uma visão mais ampla, a dos stakeholders, formalizada por Freeman (1984), que os gestores têm deveres a serem cumpridos com diversos grupos, clientes, fornecedores, empregados, comunidade, e não apenas com os proprietários, pois todos eles são afetados pelas decisões tomadas na empresa.

Um dos principais trabalhos que formalizaram o aparente conflito entre essas teorias foi o de Jensen (2001) que argumenta que o objetivo das decisões tomadas em uma empresa deve ser maximizar o valor para o acionista e, dessa forma, os demais stakeholders também terão seus objetivos atendidos. Mesmo sendo um defensor da teoria dos shareholders, Jensen (2001) afirma que a teoria apresenta suas limitações e que é impossível maximizar o valor da empresa, no longo prazo, se os gestores ignorarem ou prejudicarem algum outro agente envolvido com ela.

No Brasil, os incentivos às práticas de sustentabilidade empresarial foram reforçados em 2005 e tiveram como um dos principais órgãos fomentadores a Bolsa de Valores, Mercadorias e Futuros de São Paulo (BM\&FBOVESPA). Embora com incentivos de diferentes órgãos, ainda não há um consenso, em função de haver poucas evidências sobre quais os determinantes de SE no Brasil, se investidores valorizam as empresas classificadas como referência em SE.

Assim, assume-se que foram dois os objetivos deste artigo: o primeiro foi identificar quais são as características que se apresentam como determinantes de adesão de empresas brasileiras ao Índice de Sustentabilidade Empresarial (ISE) da BM\&FBOVESPA. O segundo consistiu em verificar se existe relação entre a adesão ao ISE e o valor das empresas.

Trabalhos recentes contribuíram com a discussão sobre o tema, como os de Barnett (2005), Lee (2006), Lo \& Sheu (2007), Artiach et al. (2010). No Brasil, Borba (2005), Cavalcante et al. (2007), Rossi Junior (2009), Nossa et al. (2009), Nunes et al. (2010), Boaventura et al. (2012), Andrade et al. (2012), Freguete \& Funchal (2012) destacaram a dificuldade de encontrar evidências convergentes sobre os fatores que influenciam as empresas em aderirem a práticas de sustentabilidade empresarial, e a relação destas práticas com o valor de mercado das empresas.

A principal contribuição deste trabalho foi a identificação de indícios de que a crise financeira sugere alteração da natureza da relação entre adesão 
ao ISE e valor de mercado das empresas brasileiras, resultado ainda não encontrado em trabalhos anteriores. Esta evidência corrobora os argumentos apresentados por Yelkikalan \& Köse (2012) de que, em períodos de crise, ameaças e oportunidades são levadas às empresas e seus efeitos sobre as práticas de responsabilidade social e ambiental podem acontecer em diferentes direções.

O presente artigo está estruturado da seguinte forma: na seção 2 descrevem-se as contribuições e o posicionamento da literatura sobre sustentabilidade empresarial, as quais fundamentam as hipóteses do estudo. Na seção 3 descrevem-se os critérios metodológicos utilizados com relação à coleta e ao tratamento dos dados. Nas seções 4 e 5 apresentam-se os principais resultados e conclusões, bem como questões para futuras pesquisas.

\section{Fundamentação Teórica e Hipóteses}

\subsection{O objetivo da empresa e a Sustentabilidade Empresarial (SE)}

Duas abordagens teóricas diferem quanto à função-objetivo de uma empresa, quais sejam, a dos shareholders e a dos stakeholders, (Jensen, 2001). Estas teorias assumem diferentes perspectivas sobre qual deve ser a Sustentabilidade Empresarial (SE), conforme será detalhado nesta seção.

A teoria dos shareholders é formalmente denominada teoria da firma, ${ }^{1}$ como destacam Boaventura et al. (2009), e está relacionada com a proposta de que o objetivo da empresa seja maximizar a riqueza dos acionistas. Os principais argumentos em favor desta teoria são apresentados por Jensen (2001) ao afirmar que, quando o valor da empresa é maximizado, todos os envolvidos serão beneficiados, e não apenas os acionistas. Outro argumento é que o objetivo de maximizar a riqueza é claro o suficiente para evitar possíveis conflitos entre diferentes públicos envolvidos com a empresa. Com relação às principais críticas desta abordagem, destacam-se as apresentadas por Sundaran \& Inkpen (2004), ao afirmarem sobre a possibilidade de os gestores expropriarem os direitos de diferentes agentes envolvidos na empresa em favor dos acionistas, que os contrataram. Estes autores argumentaram, ainda, que existem falhas nos contratos com as demais partes relacionadas.

Já a teoria dos stakeholders defende que o objetivo da empresa seja co-

\footnotetext{
${ }^{1}$ Teoria da firma: Teve seu início com o surgimento da ciência econômica, no século XVIII, com a obra de Adam Smith e autores como Coase (1937) e Jensen (2001), dentre outros, contribuíram para formalizá-la.
} 
ordenar os interesses dos demais agentes envolvidos e que as decisões dos gestores devem compreender os diferentes objetivos, os quais são estabelecidos para atender a cada um deles (Evan \& Freeman, 1993). Autores que defendem esta teoria, como Donaldson \& Preston (1995) e Campbell (1997), argumentam que ela é fundamental para que os gestores entendam que é impossível que as empresas sobrevivam sem agregar valor aos stakeholders em geral, e não apenas aos acionistas. Sua principal crítica, segundo Jensen (2001), é que ela não deixa claro como os gestores devem proceder diante dos conflitos de interesses entre as partes relacionadas. Tal argumento sugere que a teoria seja considerada incompleta para ser aplicada pelos gestores.

O termo Responsabilidade Social Corporativa, segundo Carroll (1979), deve incluir os seguintes aspectos de responsabilidade: i) econômica: como a base da pirâmide das responsabilidades, pois uma empresa não deve existir sem o lucro; ii) legal: pois é esperado que as empresas conciliem seus objetivos econômicos com base nas normas e na estrutura legal vigentes em seu país e iii) discricionariedade e filantropia: relacionadas à prática voluntária direcionada ao desejo da companhia em contribuir com a sociedade e não quando forçada pela ética, leis e interesses econômicos. Observa-se que a definição de RSC é ampla e defende que a empresa deve assumir um conjunto amplo de responsabilidades. Já Friedman (1970) destaca que a única responsabilidade social dos negócios seria puramente econômica, ou seja, a firma, ao maximizar os seus lucros, estaria gerando bem-estar para toda a sociedade.

Identifica-se que a definição de RSC, por Carroll (1979), vai além das expectativas puramente econômicas e aproxima-se da perspectiva teórica dos stakeholders. Para McWilliams \& Siegel (2000), o termo RSC se refere às ações voltadas ao bem-estar social que vão além do cumprimento de leis e da busca pela competitividade, assumindo, dessa maneira, um caráter de voluntarismo e de filantropia. Já a definição de Friedman (1970) aproximase da perspectiva dos shareholders, como também destacou Jensen (2001).

Diante tal divergência entre as perspectivas teóricas da função-objetivo da empresa, as evidências empíricas sobre a relação entre RSC e desempenho financeiro são variadas e divergentes, conforme demonstra-se a seguir.

Resultados como os de Alexander \& Buchholz (1978), e de Becchetti et al. (2005), apontam para uma perspectiva de que há uma associação negativa entre RSC e desempenho financeiro, devido ao investimento na 
primeira ser considerado alto. Dessa forma, as empresas que investem em RSC incorrem em custos adicionais, tais como condições de trabalho, adoção de práticas ambientais corretas, doações voluntárias, promoção do desenvolvimento comunitário, desenvolvimento de áreas economicamente pobres, bem como renúncia à aprovação de projetos de investimentos que não sejam socialmente responsáveis, arcando com esse custo de oportunidade.

Essa perspectiva evidencia que investimentos em RSC são contrários aos interesses dos investidores, já que realocam seus recursos escassos aos seus stakeholders externos, tal como afirmam Aupperle et al. (1985), Mcguire et al. (1988), Barnett (2005).

Uma segunda perspectiva sugere que não há associação direta entre RSC e desempenho financeiro. Ullmann (1985) sugere que há maior carência de suporte teórico para qualquer pesquisador que esperar uma relação direta entre RSC e desempenho financeiro. Este argumento sugere que a relação entre RSC e desempenho financeiro seja complexa, dada a dificuldade de controle sobre os fatores intervenientes.

Por fim, a terceira perspectiva afirma que a RSC está positivamente relacionada com o desempenho financeiro. Segundo Artiach et al. (2010), há três correntes predominantes que são consistentes com esta perspectiva. A primeira é que as vantagens de se investir em RSC são maiores que os seus custos, como destacaram Mcguire et al. (1988) e Barnett (2005). Tais vantagens seriam identificadas por empregados com moral reforçada, boa vontade, melhor relacionamento com instituições financeiras, com o governo e com investidores, traduzindo-se como maior facilidade em acesso ao capital. A segunda, a teoria dos stakeholders, defende que os investimentos em RSC geram efeitos positivos pelos participantes da gestão. A terceira, a teoria de recursos, argumenta que empresas que investem em RSC têm recursos superiores, como afirmam Alexander \& Buchholz (1978), Waddock \& Graves (1997), Clarkson et al. (2006). Essa visão sugere que apenas as empresas com recursos suficientes têm a capacidade de investir no RSC e que esses investimentos estariam positivamente associados com desempenho financeiro.

Percebe-se que os resultados de pesquisas já realizadas, em que foi analisada a relação entre RSC e desempenho financeiro, têm alcançado conclusões conflitantes. Nos estudos realizados por Lee (2006) e McWilliams \& Siegel (2000), concluiu-se que não há uma evidência de associação significativa entre RSC e desempenho financeiro. Alternativamente, Pava \& 
Krausz (1996) e Cochran \& Wood (1984) encontraram fracas evidências que sugerem uma relação positiva. Finalmente, Waddock \& Graves (1997) e Mcguire et al. (1988) concluíram que existem evidências significativas que sugerem relações positivas associadas como o desempenho financeiro. Artiach et al. (2010) argumentam que a variação entre metodologias de pesquisa provavelmente contribuiu para justificar os resultados anteriores. Outra possível fonte de divergência, conforme destacou Ullmann (1985), é a complexidade da relação entre RSC e desempenho financeiro das empresas.

\subsection{Sustentabilidade Empresarial (SE) e relação com o desempenho financeiro}

Os termos RSC e SE são frequentemente utilizados na literatura como sinônimos, no entanto, há diferenças conceituais entre eles, as quais devem ser compreendidas (Van Marrewijk, 2003, Caldelli \& Pamigiani, 2004, Wajnberg \& Lemme, 2009).

A definição de sustentabilidade empresarial (SE), segundo (Van Marrewijk, 2003), está associada com as atividades empresariais que demonstram a inclusão de aspectos sociais e ambientais na operação do negócio e nas interações com os stakeholders. Já (Wajnberg \& Lemme, 2009) contribuíram para a compreensão do termo, ao argumentarem que um conceito que está associado à sustentabilidade empresarial é o triple bottom line, proposto por (Elkington, 1998), pois defendem que SE refere à prosperidade econômica, à qualidade ambiental e à justiça social.

Verifica-se, dessa forma, que o termo sustentabilidade empresarial reflete a integração das questões socioambientais na estratégia corporativa, como forma de criar vantagens competitivas sustentáveis de longo prazo (Wajnberg \& Lemme, 2009). Assim, em linha com o conceito de triple bottom line, deve ser destacado que a expressão sustentabilidade empresarial considera a integração entre desempenho ambiental, social e financeiro.

Caldelli \& Pamigiani (2004) também destacaram que existe diferença entre SE e RSC. Para estes autores, SE é a inclusão de critérios sociais e ambientais no processo decisório da empresa, além do econômico, e que existe uma relação de integração, e não de conflitos. Já RSC, os autores destacaram, refere-se à predisposição da empresa em assumir a responsabilidade diante dos impactos causados na sociedade.

De acordo com o relatório da Organização das Nações Unidas sobre o meio ambiente e desenvolvimento, elaborado em 1987, a SE é conside- 
rada um negócio e estratégia de investimento que procura utilizar as melhores práticas empresariais para conhecer e equilibrar as necessidades dos interessados (stakeholders) de uma empresa. Esta definição, assim como destacada por Artiach et al. (2010), implica na complexa tarefa de fornecer resultados competitivos no curto prazo, procurando, ao mesmo tempo, proteger, manter e aumentar os recursos naturais e humanos necessários no futuro.

No Brasil, de acordo com a BM\&FBOVESPA (2012), a partir da década de 1990 iniciou-se uma tendência de os investidores procurarem empresas socialmente responsáveis, sustentáveis e rentáveis para aplicarem seus recursos. Tais aplicações, denominadas investimentos socialmente responsáveis (ISR), consideram que empresas sustentáveis geram valor para o acionista no longo prazo, pois estarão mais preparadas para enfrentar riscos econômicos, sociais e ambientais. Motivada por essa justificativa, em 2005, a BM\&FBOVESPA, em parceria com outras instituições, tais como a Associação Brasileira das Entidades Fechadas de Previdência Complementar (ABRAPP), a Associação Nacional dos Bancos de Investimento (ANBID), a Associação dos Analistas e Profissionais de Investimento do Mercado de Capitais (APIMEC), o Instituto Brasileiro de Governança Corporativa (IBGC), o International Finance Corporation (IFC) e o Instituto ETHOS, criado em 1999, além do Ministério do Meio Ambiente, uniu esforços para criar um índice de ações que fosse uma referência para os investimentos socialmente responsáveis. Trata-se do Índice de Sustentabilidade Empresarial (ISE).

O índice é composto por uma carteira de empresas que se comprometeram a desenvolver ações de sustentabilidade empresarial e que responderam a um questionário elaborado pelo Centro de Estudos de Sustentabilidade da Fundação Getúlio Vargas (CES-FGV). Tal questionário parte do conceito do Triple Bottom Line, que envolve a avaliação de elementos ambientais, sociais e econômico-financeiros de forma integrada, conforme mencionado anteriormente. Cabe ressaltar que, embora a criação do ISE tenha ocorrido em 2005, uma das primeiras organizações a fomentar a performance social e/ou ambiental nas organizações foi o Instituto Brasileiro de Análises Sociais e Econômicas (IBASE), criado em 1997.

O ISE consiste em um índice criado nos moldes do Dow Jones Sustainability Index (DJSI), e do FTSE4 Good Series e Johannesburg Stock Exchange SRI Index. De acordo com dados da BM\&FBOVESPA, a criação do ISE visa promover um ambiente de investimento compatível com as 
demandas de desenvolvimento sustentável da sociedade contemporânea. Além disso, objetiva estimular os investimentos que consideram aspectos de governança corporativa e sustentabilidade empresarial, eficiência econômica, equilíbrio ambiental e justiça social.

Este artigo concentra-se na corrente de pesquisa que investiga a relação entre a sustentabilidade empresarial (SE), avaliada pela proxy do ISE da BM\&FBOVESPA, e o desempenho financeiro, avaliado por um indicador de mercado que reflete a percepção de valor do acionista. Além disso, concentra-se na identificação de possíveis variáveis que influenciam uma empresa a aderir ao ISE.

Conforme destacaram Wajnberg \& Lemme (2009), diferentes trabalhos já foram desenvolvidos buscando encontrar uma relação entre o desempenho financeiro corporativo e o desempenho socioambiental, mas as evidências apresentadas apontam para resultados variados e divergentes. Para estes autores, as motivações econômico-financeiras para a inclusão da sustentabilidade no negócio dependem tanto do contexto da firma quanto do setor industrial em que ela está inserida. No Brasil, embora com poucas evidências, diferentes trabalhos foram desenvolvidos, a fim de verificar as variáveis que influenciam as empresas investirem em SE e se tais investimentos têm relação com o valor da empresa. Por isso, pretende-se contribuir com os trabalhos já realizados, tais como os de Brito (2005), Borba (2005), Marom (2006), Rossi Junior (2009), Nunes et al. (2010), Perera et al. (2011), Freguete \& Funchal (2012).

Nunes et al. (2010) verificaram que os determinantes de SE são o tamanho e o setor de atuação da empresa. Rossi Junior (2009) identificou que as empresas classificadas no ISE são maiores e mais rentáveis, quando comparadas com as empresas não listadas. Já Andrade et al. (2012) encontraram resultados semelhantes aos dos trabalhos anteriores e identificaram que a taxa de crescimento da receita e o período de crise financeira de 2008 apresentaram relação negativa com a probabilidade de as empresas estarem listadas no ISE.

No que diz respeito à relação entre adesão ao ISE e valor das empresas no Brasil, as evidências são conflitantes e apresentadas em diferentes abordagens metodológicas.

Borba (2005) realizou um estudo, durante o período de 2000 a 2002, e não encontrou relação significativa entre sustentabilidade empresarial e performance financeira das empresas. Cavalcante et al. (2007) compararam o retorno das ações entre empresas listadas e não listadas no ISE, no 
período entre 2005 e 2006 e não encontraram evidências de maior valor às ações de empresas com adesão ao ISE. Perera et al. (2011) encontraram, no período de 2005 a 2008, que a variação nos indicadores de desempenho não é significativa quando a empresa recebe o certificado de socialmente responsável. Por outro lado, Rossi Junior (2009) constatou, para o período de 2005 a 2007, que existe um aumento de valor das empresas que adotaram políticas de sustentabilidade empresarial.

Identifica-se que os trabalhos desenvolvidos no Brasil, aqui apresentados, são divergentes a respeito dos fatores que influenciam as empresas a aderirem ao ISE e se tal adesão apresenta relação com o valor da empresa, conforme esperado pela teoria (Van Marrewijk, 2003, Caldelli \& Pamigiani, 2004). Como características comuns a estes trabalhos, nota-se que eles utilizam um período recente em relação à criação do ISE, em 2005, e período anterior à crise financeira de 2008. Considerou-se, neste trabalho, que um dos argumentos apresentados por Rajan \& Luigi (1998), qual seja, o de que em períodos de crise os investidores tendem a questionar o tipo de governança que é praticado pela gestão e que, em períodos de crescimento econômico, eles tendem a se despreocupar com tais questões, não foi investigado em nenhum dos estudos, em alguns casos devido ao período amostral.

Assim, este artigo pretende contribuir para a construção de evidências sobre as possíveis variáveis que afetam a adesão de uma empresa ao ISE e verificar se existe relação entre adesão ao ISE e valor de mercado da empresa. De forma complementar, visa identificar se o período de crise financeira de 2008 afetou a natureza dessas relações.

\subsection{Desenvolvimento de hipóteses}

A seguir apresentam-se as varáveis analisadas, bem como as hipóteses de pesquisa que foram testadas neste trabalho. Cabe ressaltar que se utilizou o trabalho de Artiach et al. (2010) como referência, no entanto, foram realizadas adaptações, entendidas como necessárias, ao mercado brasileiro, principalmente ao fato do ISE estar orientado para a perspectiva do triple bottom line (Wajnberg \& Lemme, 2009, Bolsa de Mercadorias e Valores de São Paulo (BM\&FBOVESPA), 2012). Nesta perspectiva, conforme descrito anteriormente, o fato de uma empresa estar listada no ISE representa que ela respondeu ao questionário e atendeu aos critérios para a inclusão no índice. 


\section{Tamanho da empresa}

De acordo com Artiach et al. (2010), o tamanho da empresa pode ser um importante determinante de SE. A justificativa é que grandes empresas estão mais visíveis politicamente e, assim, chamam mais a atenção do público em geral, do governo e de demais interessados. Adicionalmente, Artiach et al. (2010) destacaram que as grandes empresas são mais propensas a criar maiores problemas sociais e ambientais devido à escala e ao destaque de suas atividades. Como exemplo, estes autores citam que a emissão de poluentes, em certa medida, será uma função do tamanho e volume das operações. As evidências de relação positiva foram encontradas por Nunes et al. (2010).

Dessa forma, formula-se a seguinte hipótese:

$\mathbf{H}_{1}$ : O tamanho da empresa e a SE são relacionados.

\section{Endividamento}

Segundo Artiach et al. (2010), como fornecedores de capital para a empresa, os credores compõem o grupo de atores com maior poder para resolver suas preocupações do que as partes com menos poder, como empregados ou comunidade em geral. A partir desta perspectiva, espera-se que, quando o endividamento da empresa aumenta, haja uma ênfase sobre as reivindicações dos credores sobre a dos demandantes com menos poder, o que sugere uma relação negativa entre endividamento e SE.

No entanto, conforme destacado por Wajnberg \& Lemme (2009), diante das iniciativas internacionais de finanças sustentáveis elaboradas pelo Equator Principles e United Nations Principles for Responsible Investment, o setor financeiro brasileiro tem sido um indutor de práticas ambientais e sociais nas empresas. Segundo Mattos (2007), o Brasil é o país emergente com o maior número de bancos que seguem aos princípios de sustentabilidade. A Federação Brasileira de Bancos (FEBRABAN) e o setor bancário nacional apoiaram a Conferência das Nações Unidas sobre Meio Ambiente e Desenvolvimento Sustentável (Rio + 20) e, dentre as diferentes diretrizes de sustentabilidade, encontra-se a Matriz de Indicadores para o Protocolo Verde. ${ }^{2}$ Segundo Federação Brasileira de Bancos (FEBRABAN) (2013), este Protocolo Verde, assinado em 2009, inclui princípios e diretrizes que

\footnotetext{
${ }^{2} \mathrm{~A}$ matriz de indicadores para o Protocolo Verde é disponibilizada no link: http://www.febraban.org.br/protocoloverde/Matriz_Indicadores_ Febraban_161210_alteraesaceitas.pdfacessoem30/01/2013.
} 
estimulam os bancos a oferecerem linhas de financiamento que fomentem a qualidade de vida da população e o uso sustentável dos recursos naturais. Dessa forma, verifica-se que tais diretrizes sugerem uma relação positiva entre endividamento das empresas e SE, devido aos diferentes incentivos de financiamento voltados para os negócios que envolvem a sustentabilidade empresarial.

No Brasil, Teixeira et al. (2011) encontraram evidências de relação negativa entre SE e endividamento. Segundo estes autores, seus resultados são robustos e coerentes com a teoria de seleção adversa, e consideraram que a adesão de uma empresa ao ISE mitiga os problemas decorrentes de informação assimétrica, conforme desenvolveram Myers \& Majluf (1984). Além disso, Teixeira et al. (2011) apresentaram evidências de relação negativa entre adesão ao ISE e risco sistemático das ações da empresa. Diante destas divergentes perspectivas, a segunda hipótese de pesquisa é desenvolvida da seguinte forma:

$\mathbf{H}_{2}$ : Existe relação entre o endividamento e a SE nas empresas do mercado brasileiro.

\section{Capacidade de financiamento}

Sob o ponto de vista da teoria dos stakeholders os gestores devem atender às necessidades de todos eles. No entanto, em períodos de baixa rentabilidade, a demanda econômica terá prioridade sobre os interesses sociais e ambientais (Ullmann, 1985). Assim, a performance econômica da empresa influencia sua capacidade de realizar programas com foco na demanda social e ambiental. O fluxo de caixa livre é considerado uma medida de liquidez da firma e de folga financeira (Artiach et al., 2010). No entanto, sob a perspectiva de sustentabilidade empresarial, de acordo com o triple bottom line, proposto por Elkington (1998) e alinhado com os critérios de adesão ao ISE, a empresa que tiver melhor capacidade de financiamento terá uma maior propensão em aprovar novos projetos atrativos economicamente, especialmente aqueles relacionados à sustentabilidade empresarial.

Isto sugere a seguinte hipótese:

$\mathbf{H}_{3}$ : Existe relação entre a capacidade de financiamento de uma empresa e a SE. 


\section{Rentabilidade e crescimento das vendas}

Segundo Barnett (2005), uma das vantagens em investir em SE seria identificada por empregados com moral reforçada, boa vontade, melhor relacionamento com o mercado consumidor, traduzindo-se como maior rentabilidade e facilidade de crescimento das vendas.

No Brasil, Perera et al. (2011) e Freguete \& Funchal (2012) não encontraram evidências de relação significativa entre práticas de sustentabilidade e indicadores de rentabilidade. Dessa forma, são formuladas as seguintes hipóteses:

$\mathbf{H}_{4}$ : H4: Existe relação entre a rentabilidade e a SE.

$\mathbf{H}_{5}$ : Existe relação entre o nível de crescimento das vendas e a SE.

\section{Crise financeira mundial}

Os estudos sobre crise financeira têm destacado que um grande número de empresas apresenta um pior desempenho financeiro do que outras empresas durante períodos de crise, no entanto, não explicam porque isso acontece, uma vez que todas elas estão expostas aos mesmos fatores macroeconômicos (Liu et al., 2010). Estes mesmos autores destacaram que uma crise financeira é um evento não previsível e que é extremamente difícil para as firmas ajustarem suas estruturas de governança frente a uma futura crise financeira. Já para Rajan \& Luigi (1998), os investidores tendem a ignorar a falta de uma adequada estrutura de governança durante um boom da economia, entretanto, uma vez que a crise financeira se instala e as expectativas de retorno falham substancialmente, começam a questionar o sistema de governança.

Uma matéria publicada no site The Economist, no dia 14 de maio de 2009 , enfatizou que a crise financeira de 2008 foi provocada por um ataque de irresponsabilidade empresarial e, por isso, foi uma evidência de que as empresas devem não apenas manter os seus compromissos com a sustentabilidade, mas ir além, até mesmo para recuperarem a confiança no negócio e provarem que não são apenas motivadas pela visão de curto prazo, depois de todo o ocorrido. Para Mcguire et al. (1988), as empresas com programas de sustentabilidade empresarial têm maiores chances de operar com investimentos bem lastreados e com uma estrutura de capital 
com menor risco e, por isso, apresentam menores chances de serem abaladas durante um momento de crise econômica.

Já Souto (2009) destaca que a crise financeira de 2008 é uma evidência de que a as práticas de SE não devem ser um modismo temporário, e sim uma ferramenta de gestão que deve se renovar constantemente no longo prazo e que o mundo ainda está longe da situação ideal de um quadro global e único para tais práticas. Yelkikalan \& Köse (2012) desenvolveram um modelo teórico em que se admite que, em períodos de crise, ameaças e oportunidades são levadas às empresas, e seus efeitos sobre as práticas de responsabilidade social e ambiental podem acontecer em diferentes direções.

No Brasil, as evidências apresentadas por Freguete \& Funchal (2012) apontaram que, durante a crise de 2008, a adesão ao ISE não interferiu no desempenho financeiro das empresas.

Diante da divergência destas evidências empíricas, e sob a perspectiva do triple bottom line de sustentabilidade empresarial, elaborou-se a seguinte hipótese:

$\mathbf{H}_{6}$ : Existe relação entre crise financeira de 2008 e os determinantes de adesão ao ISE.

\subsection{Relação entre ISE e valor da empresa}

A literatura aponta para uma divergência nas evidências empíricas sobre a relação entre desempenho socioambiental e desempenho financeiro corporativo (Ullmann, 1985, Wajnberg \& Lemme, 2009, Artiach et al., 2010). No entanto, e em linha com a perspectiva do triple bottom line, considerou-se, neste artigo, que os investimentos de uma empresa em negócios voltados para a sustentabilidade ambiental e social são motivados de forma integrada com a perspectiva econômica e financeira, e não em forma de conflito entre tais dimensões (Van Marrewijk, 2003, Caldelli \& Pamigiani, 2004). Conforme destacado por Cavalcante et al. (2009), a sustentabilidade corporativa é atrativa para os investidores, pois tem como objetivo aumentar o valor das ações no longo prazo. No entanto, os resultados encontrados no mercado brasileiro são inconclusivos. A relação positiva foi encontrada por Rossi Junior (2009). Já Nossa et al. (2009), Perera et al. (2011) e Freguete \& Funchal (2012) não encontraram evidências de relação significativa entre sustentabilidade empresarial e valor de mercado das empresas.

194 Rev. Bras. Finanças (Online), Rio de Janeiro, Vol. 11, No. 2, June 2013 
Assim, e considerando os argumentos desenvolvidos no item 2.3.6, surgiram as seguintes hipóteses.

$\mathbf{H}_{7}$ : A adesão ao ISE tem relação com o valor de mercado da empresa.

$\mathbf{H}_{8}$ : A crise financeira de 2008 exerceu influência na relação entre adesão ao ISE e valor da empresa.

\section{Metodologia}

\subsection{Coleta de dados}

A amostra considerou um período de seis anos, entre 2006 e 2011. Para compor o grupo de empresas estudadas, foram considerados dois subgrupos, o de empresas listadas e o de não listadas no ISE. Para o grupo de empresas não listadas, foram escolhidas as empresas do Índice BM\&FBOVESPA (IBOVESPA) que não pertenceram ao ISE durante o período analisado. Assim, foram consideradas como observações válidas aquelas advindas de empresas que estiveram listadas no ISE ou no IBOVESPA em, pelo menos, um dos anos do período amostral. Para tanto, considerou-se a data de 31 de dezembro de cada ano, para identificar as empresas que compuseram cada um dos índices.

Cabe ressaltar que, conforme discutido na seção 2.2, o ISE é um índice que parte do conceito do triple bottom line. Por isso, e conforme destacaram Cavalcante et al. (2009), o ISE propõe-se a focar na sustentabilidade empresarial, e não apenas na sustentabilidade ambiental e/ou social. As hipóteses de pesquisa apresentadas na seção 2.3 foram elaboradas partindo desta premissa de integração, e não de exclusão, entre as diferentes dimensões que compõem o ISE, social, ambiental e econômico ou financeiro.

Consideraram-se apenas as instituições não financeiras. Esta restrição justifica-se, uma vez que as instituições financeiras apresentam contas diferenciadas em seus demonstrativos e características peculiares deste setor de atividade.

Para evitar efeitos inflacionários nas variáveis observadas, todos os valores foram corrigidos pelo IGP, na data base de 31/12/2011.

Para a classificação dos setores, recorreu-se ao critério da Economática e, na Tabela 1, apresenta-se a quantidade de empresas classificadas por 
setor, presentes na amostra. Além da classificação setorial, as empresas foram divididas em setores de alto ou moderado impacto ambiental, segundo classificação da BM\&FBOVESPA. Esta classificação considera a dimensão ambiental do setor em que a empresa está inserida. Assim, o setor de "impacto moderado" considera os seguintes setores: aluguel de carros, análises e diagnósticos, comércio, hotelaria, jornais/livros e revistas, livrarias e papelarias, telefonia fixa, TV por assinatura, utilidades domésticas e vestuário. Já o setor de "alto impacto" considera os demais setores, tais como mineração, siderurgia, papel e celulose e energia elétrica, dentre outros de impacto ambiental considerado alto.

A justificativa desta classificação é a de que empresas com alta evidenciação de informações socioambientais participam de setores ambientalmente sensíveis ou poluidores em potencial do meio ambiente. Critério semelhante foi utilizado por Nunes et al. (2010). Outra justificativa para incluir uma análise setorial neste estudo é fundamentada nos argumentos de Reed (2001) e Wajnberg \& Lemme (2009), de que não é possível construir uma justificativa de negócio genérica para que uma empresa incorpore a sustentabilidade nas suas atividades operacionais. Por isso, estes autores consideraram que as motivações seriam específicas de cada empresa e do contexto específico no nível da empresa, do setor e do país.

Tabela 1

Classificação setorial e dimensão ambiental

\begin{tabular}{lcc}
\hline Setor & Qtd. & Dimensão ambiental \\
\hline 1 - Construção & 7 & Alto impacto \\
2 - Energia elétrica & 13 & Alto impacto \\
3 - Máquinas industriais & 2 & Alto impacto \\
4 - Mineração & 2 & Alto impacto \\
5 - Papel e celulose & 4 & Alto impacto \\
6 - Petróleo e gás & 4 & Alto impacto \\
7 - Química & 2 & Alto impacto \\
8 - Siderurgia \& metalurgia & 6 & Alto impacto \\
9 - Telecomunicações & 7 & Alto impacto \\
10 - Alimentos e bebidas & 6 & Impacto moderado \\
11 - Comércio & 5 & Impacto moderado \\
12 - Software e dados & 1 & Impacto moderado \\
13 - Têxtil & 1 & Impacto moderado \\
14 - Transporte e serviços & 5 & Impacto moderado \\
15 - Veículos e peças & 2 & Impacto moderado \\
16 - Outros & 14 & Impacto moderado \\
Total & 81 & \\
\hline Fonte: Dados da pesquisa & &
\end{tabular}


As fontes utilizadas para coleta de dados foram a Economática e a BM\&FBOVESPA. Após o levantamento dos dados, foram excluídas as empresas que não apresentaram as informações necessárias para a realização da pesquisa. Assim, com o objetivo de obter uma maior quantidade de observações, foi constituído um painel desbalanceado de dados, em que a quantidade de observações por empresa variou entre um a seis períodos, no intervalo de 31/12/2006 a 31/12/2011.

\subsection{Análise dos determinantes de adesão das empresas ao ISE}

Para identificar quais são as variáveis que afetaram a adesão das empresas brasileiras no índice de sustentabilidade empresarial, recorreu-se ao modelo Logit. Este método foi utilizado para avaliar a probabilidade de uma característica da empresa influenciar a listagem ou não no ISE.

Dessa forma, com base em trabalhos tais como os de Alexander \& Buchholz (1978), Mcguire et al. (1988), Waddock \& Graves (1997), Barnett (2005), Clarkson et al. (2006), Artiach et al. (2010), Nunes et al. (2010), Andrade et al. (2012), foi proposto o seguinte modelo para identificar os determinantes de sustentabilidade empresarial no Brasil.

$$
\begin{aligned}
I S E_{i t}= & B_{0}+B_{1} \text { LnAt }_{i t}+B_{2} \text { Endiv }_{i t}+B_{3} \text { Rentabilidade }_{i t} \\
& +B_{4} \text { Capac.Financ } . i t+B_{5} \text { Oport.Cresc } . i t_{1}+B_{6} \text { Altoimp }_{i t} \\
& +B_{7} \text { CrescRec }_{i t}+B_{8} \text { Crise }_{i t}+u_{i}+\epsilon_{i t}, \\
& i=1, \ldots, N \text { e } t=1, \ldots, T
\end{aligned}
$$

em que $u_{i}$ é a heterogeneidade não observada da empresa $i$ e $\epsilon_{i t}$ é o termo de erro aleatório.

A descrição das variáveis inclusas na equação (1) é apresentada na Tabela 2, na seção 3.4 .

Para a estimação dos parâmetros, recorreu-se ao método Logit aplicado para dados em painel com a estimação robusta. Segundo Cameron \& Trivedi (2010), a estimação robusta relaxa os pressupostos de heterocedasticidade e autocorrelação serial dos resíduos. Os testes LM de Breush-Pagan e o de Hausman foram utilizados para comparar entre modelo pooled ou dados em painel, e modelos de efeitos fixos ou aleatórios, respectivamente.

Destaca-se que um pré-requisito para a inclusão de uma empresa ao ISE é a resposta voluntária ao questionário enviado pela BM\&FBOVESPA. Por isso, diante da possibilidade das razões de não resposta serem correla- 
cionadas com os regressores, espera-se mitigar o possível efeito da endogenia com a aplicação dos modelos de dados em painel. O modelo de efeitos fixos, por exemplo, permite que possíveis variáveis omitidas sejam correlacionadas com os regressores, no entanto, assume que são constantes no tempo.

\subsection{Análise da relação entre sustentabilidade empresarial (SE) e valor da empresa}

Para verificar a existência da relação entre adesão ao ISE e valor da empresa, empregou-se o modelo apresentado na equação (2). O modelo foi desenvolvido com base na literatura relacionada, tal como o trabalho de Lo \& Sheu (2007), Rossi Junior (2009), Freguete \& Funchal (2012).

$$
\begin{aligned}
\text { Valor }_{i t}= & \beta_{0}+\beta_{1} I S E_{i t}+\beta_{2}{\text { Crise } 2008_{t}} \\
& +\beta_{3} I S E_{i t} * \text { Crise }_{2008_{t}}+\beta_{4} I S E_{i t} * \text { PosCrise }_{t} \\
& +\ldots . .+\beta_{5} \text { LnAt }_{i t}+\beta_{6} \text { ROA }_{i t} \\
& +\beta_{7} \text { Endiv }_{i t}+\sum_{k=1}^{17} \beta_{k+7} \text { Setor }_{i}+u_{i}+\epsilon_{i t}
\end{aligned}
$$

em que $I S E_{i t}$, Crise $2008_{i t}, I S E_{i t} *$ Crise $2008_{i}$ e $I S E_{i t} *$ PosCrise $_{i}$ representam as variáveis de interesse. Já as variáveis Lnat, $R O A$, Endiv e Setor representam as variáveis de controle. A descrição das variáveis é apresentada na Tabela 2, na seção 3.4.

Para a estimação dos parâmetros, recorreu-se ao método de dados em painel, com a estimação robusta. Segundo Cameron \& Trivedi (2010), esse procedimento é recomendado na presença de heterocedasticidade e de autocorrelação serial dos resíduos. Procedimento semelhante também foi utilizado por Freguete \& Funchal (2012). Os testes LM de Breush-Pagan e o de Hausman foram utilizados para comparar entre modelo pooled ou dados em painel, e modelos de efeitos fixos ou aleatórios, respectivamente.

\subsection{Descrição das variáveis}

Na Tabela 2 apresenta-se uma síntese do procedimento de cálculo das variáveis. A mesma foi construída com base nos argumentos dos seguintes autores: Artiach et al. (2010), Chung \& Pruitt (1994), Famá \& Barros (2000), Freguete \& Funchal (2012), Liu et al. (2010), Lo \& Sheu (2007), 
Nunes et al. (2010), Rossi Junior (2009). Freguete \& Funchal (2012) utilizaram o logaritmo natural do valor de mercado da empresa (LnVM) ao invés de $V M / A T_{i t}$.

Tabela 2

Descrição operacional das variáveis

\begin{tabular}{|c|c|c|}
\hline & Sigla & Variável \\
\hline $\begin{array}{l}\text { Sustentabilidade } \\
\text { empresarial }\end{array}$ & $I S E_{i t}$ & $\begin{array}{l}\text { Dummy - (1) se está listada no ISE; (0) caso } \\
\text { contrário. }\end{array}$ \\
\hline \multirow[t]{3}{*}{ Valor } & $Q$ Tobin $_{i t}$ & $\begin{array}{l}Q \text { de Tobin da empresa } i \text { no período } t \text {. } \\
\text { Medida de valor de mercado da companhia, } \\
\text { obtido pela expressão }[(V M O+V M A P+ \\
D I V T) /(A T)] \text {, em que } V M O=\text { valor de } \\
\text { mercado das ações ordinárias; } V M A P=\text { valor } \\
\text { de mercado das ações preferenciais; } D I V T= \\
\text { valor contábil das dívidas e } A T \text { representa o } \\
\text { valor do ativo total. }\end{array}$ \\
\hline & $V M / A T_{i t}$ & $\begin{array}{l}\text { Razão entre valor de mercado ativo total da em- } \\
\text { presa } i \text { no período } t \text {. }\end{array}$ \\
\hline & $M / B_{i t}$ & Market to Book da empresa $i$ no período $t$. \\
\hline Tamanho & $L n A t_{i t}$ & Logaritmo neperiano do ativo total \\
\hline \multirow[t]{2}{*}{ Endividamento } & $E N D I V_{i t}$ & Endividamento bruto sobre o ativo total. \\
\hline & $E N D C P_{i t}$ & $\begin{array}{l}\text { Endividamento de curto prazo sobre o ativo to- } \\
\text { tal. }\end{array}$ \\
\hline Rentabilidade & $\begin{array}{l}R O A_{i t} \\
R O E_{i t}\end{array}$ & $\begin{array}{l}\text { Rentabilidade sobre o ativo total da empresa } i \\
\text { no período } t \text {. } \\
\text { Rentabilidade sobre o patrimônio líquido }\end{array}$ \\
\hline $\begin{array}{l}\text { Capacidade de } \\
\text { financiamento }\end{array}$ & $\overline{F C L_{i t}}$ & Fluxo de caixa livre sobre ativo total \\
\hline Setor & AltoImpacto $_{i}$ & $\begin{array}{l}\text { Conjunto de variáveis binárias, indicando o } \\
\text { setor da empresa } i \text {, com base no critério da } \\
\text { Economática. } \\
\text { Variável binária indicando se o setor é de alto } \\
\text { impacto ambiental }(1) \text { e }(0) \text { se for de impacto } \\
\text { moderado. }\end{array}$ \\
\hline $\begin{array}{l}\text { Crescimento } \\
\text { da receita }\end{array}$ & CrescRec $_{i t}$ & $\begin{array}{l}\text { Variação anual da receita líquida da empresa } i \text {, } \\
\text { no período } t \text {, em relação a } t-1 \text {. }\end{array}$ \\
\hline Crise & Pós-Crise & $\begin{array}{l}\text { Dummy indicando a crise financeira de } 2008(1) \\
\text { e (0) para os demais anos }(2006,2007,2009 \text {, } \\
2010 \text { e 2011) } \\
\text { Dummy indicando o período pós-crise finan- } \\
\text { ceira de 2008. (1) para os anos de } 2009,2010 \text { e } \\
2011 \text { e (0) para os anos anteriores. }\end{array}$ \\
\hline
\end{tabular}

Fonte: Elaborada pelos autores.

\section{Resultados e discussão}

Na Tabela 3 observa-se a quantidade de empresas selecionadas na amostra pertencente ao ISE, distribuídas ao longo do período analisado. 
Tabela 3

Distribuição das empresas no ISE, durante os anos de 2006 a 2011

\begin{tabular}{lccc}
\hline Ano/N & Listadas ISE & Não listadas & Total \\
\hline 2006 & 26 & 45 & 71 \\
2007 & 26 & 50 & 76 \\
2008 & 23 & 53 & 76 \\
2009 & 29 & 44 & 73 \\
2010 & 29 & 45 & 74 \\
2011 & 29 & 43 & 72 \\
\hline Total & 162 & 280 & 442 \\
\hline
\end{tabular}

Identifica-se, por meio dos dados da Tabela 3, que o ano da crise financeira de 2008 apresentou a menor quantidade de empresas listadas no ISE, o que sugere que o nível de investimentos em sustentabilidade empresarial pode variar conforme o ambiente de crise financeira. No entanto, cabe ressaltar que é voluntária a resposta ao questionário do ISE e que possíveis fatores não relacionados à decisão de investimentos em SE podem afetar a quantidade de questionários respondidos anualmente.

Nas Tabelas 4 e 5 apresentam-se estatísticas descritivas dos dados coletados, levando-se em conta a amostra total, o grupo de empresas listadas no ISE e não listadas, e a diferença de médias por ano.

$\mathrm{Na}$ Tabela 4 destaca-se que as empresas listadas no ISE apresentaram, em média, maiores níveis de rentabilidade sobre o patrimônio líquido e sobre o ativo total, porém, apresentaram um menor valor para as métricas de valor de mercado, tais como $Q$ de Tobin, $V M / A T$ e $M / B .^{3}$ Esta relação não foi significativa nos anos de 2006 e 2007, porém, para os anos de 2009 e 2010, as empresas listadas no ISE, com valores não significativos para ROE e ROA, obtiveram menores rentabilidades, quando comparadas com as empresas não listadas.

Em 2009, 2010 e 2011, os valores de mercado das empresas listadas apresentaram uma média menor que as empresas não listadas. Os dados mostram que, no ano de 2008, caracterizado pela crise financeira mundial e desvalorização de grande parte das ações na bolsa brasileira, a queda de valor de mercado das empresas não listadas foi percentualmente maior em relação à queda das empresas listadas no ISE, em relação ao ano de 2007, o que está coerente com os argumentos apresentados por Mcguire et al. (1988) sobre a relação entre SE e valor em período de crise financeira.

\footnotetext{
${ }^{3}$ Os dados apresentados na Tabela 4 foram winsorizados a um percentual de $5 \%$. Esta técnica também foi aplicada nos trabalhos de Artiach et al. (2010) e Freguete \& Funchal (2012), com o objetivo de aumentar a robustez dos resultados.
} 
Tabela 4

Comparação de médias para o painel de empresas listadas e não listadas no ISE, por ano

\begin{tabular}{|c|c|c|c|c|c|c|c|c|c|}
\hline Variável & ISE & $\mathrm{N}$ & $2006 / 2011$ & 2006 & 2007 & 2008 & 2009 & 2010 & 2011 \\
\hline \multirow[t]{2}{*}{$Q$ Tobin } & 0 & 259 & $1,82 *$ & 1,84 & 2,1 & 1,37 & $2,06^{*}$ & $1,98^{*}$ & 1,67 \\
\hline & 1 & 162 & $1.55 *$ & 1,74 & 1,93 & 1,33 & $1,52 *$ & $1,44 *$ & 1,35 \\
\hline \multirow[t]{2}{*}{$V M / A T$} & 0 & 271 & $120,14 *$ & 130,43 & 151,21 & 67,57 & $142,75^{*}$ & $134,40 *$ & 101,62 \\
\hline & 1 & 162 & $96,18 *$ & 133,75 & 128,33 & 65,29 & $89,94 *$ & $84,31 *$ & 76,29 \\
\hline \multirow[t]{2}{*}{$M / B$} & 0 & 257 & $3,38^{*}$ & 3,5 & 3,83 & 2,34 & $3,89 *$ & $3,93^{*}$ & 2,94 \\
\hline & 1 & 160 & $2.84 *$ & 3,94 & 3,7 & 2,53 & $2,71^{*}$ & $2,36^{*}$ & 1,99 \\
\hline \multirow[t]{2}{*}{$R O A$} & 0 & 279 & $5,93 *$ & $6,21 *$ & 7,14 & 3,46 & 7,18 & 7,33 & 5,37 \\
\hline & 1 & 162 & $7.18 *$ & $9,44^{*}$ & 9,55 & 4,82 & 6,5 & 6,94 & 6,01 \\
\hline \multirow[t]{2}{*}{$R O E$} & 0 & 267 & 16,83 & 17,75 & $17,19^{*}$ & 13,54 & 19,67 & 19,26 & 14,13 \\
\hline & 1 & 160 & 18.74 & 23,74 & $24,22 *$ & 16,31 & 16,13 & 18,47 & 14,27 \\
\hline \multirow[t]{2}{*}{$F C X$} & 0 & 259 & $12,95 *$ & 14,69 & 12,67 & 13,36 & 12,34 & 12,98 & 12,11 \\
\hline & 1 & 158 & $14.51 *$ & 16,62 & 14,67 & 15,7 & 12,85 & 14,35 & 13,43 \\
\hline \multirow[t]{2}{*}{$T A M$} & 0 & 280 & $15,87 *$ & 15,72 & $15,67 *$ & $15,86^{*}$ & $15,89 *$ & $16,02 *$ & $16,12 *$ \\
\hline & 1 & 162 & $16.48 *$ & 16,19 & $16,35^{*}$ & $16,45^{*}$ & $16,55^{*}$ & $16,65 *$ & $16,64^{*}$ \\
\hline \multirow[t]{2}{*}{$E N D I V$} & 0 & 280 & 29,48 & 28,49 & 25,16 & 31 & 29,3 & 30,01 & 33,33 \\
\hline & 1 & 162 & 30.41 & 28,51 & 30,1 & 34,17 & 31,74 & 28,82 & 29,65 \\
\hline \multirow[t]{2}{*}{$E N D C P$} & 0 & 275 & $31,08^{*}$ & $32,79 *$ & $34,27 *$ & $33,01 *$ & $31,04 *$ & 24,68 & $29,69 *$ \\
\hline & 1 & 160 & $22.12 *$ & $24,99^{*}$ & $21,30 *$ & $21,81^{*}$ & $23,04^{*}$ & 21,56 & $20,08^{*}$ \\
\hline \multirow[t]{2}{*}{ CRESC.REC } & 0 & 269 & $29,23^{*}$ & 15,43 & $35,37 *$ & $30,84^{*}$ & 15,23 & $24,63 *$ & $16,73^{*}$ \\
\hline & 1 & 162 & $8.66^{*}$ & 11,25 & $6,60 *$ & $9,02 *$ & 9,33 & $14,90 *$ & $1,76^{*}$ \\
\hline
\end{tabular}

*Valores significativos ao teste de comparação de médias a até $10 \%$ de probabilidade, pelo teste

$t$ de student e que também levou em conta a diferença de variâncias dos grupos.

Fonte: Dados da pesquisa.

Embora em um nível descritivo, estas evidências contrariam os argumentos de que a adesão ao ISE esteja positivamente relacionada com o valor e desempenho das empresas.

Para as demais características em análise, em termos médios, identificou-se que as empresas listadas no ISE apresentaram tamanhos maiores, níveis de fluxo de caixa livre maiores, níveis de endividamento menores e menor taxa de crescimento de vendas e valor de mercado. Estes resultados são semelhantes aos apresentados por Alexander \& Buchholz (1978), Waddock \& Graves (1997), Clarkson et al. (2006).

No intuito de analisar casos específicos de empresas que decidiram entrar ou sair do ISE, especificamente o impacto sobre a variável $Q$ de Tobin, foi feita uma análise descritiva, a qual é apresentada na Tabela 5. Os resultados demonstraram que, de 24 empresas que decidiram pela adesão ao ISE, 16 obtiveram um incremento positivo no $Q$ de Tobin, no ano da entrada. Por outro lado, das empresas que decidiram pela saída do ISE, num total de 13 observações, 11 apresentaram variação negativa no $Q$ de Tobin. Tais resultados sugerem que a percepção de valor da empresa pelo investidor, em relação ao período anterior, pode afetar a escolha pela entrada ou saída da empresa no ISE. 
Tabela 5

Variação do $Q$ de Tobin diante da decisão de entrada ou de saída no ISE

\begin{tabular}{lccccccc}
\hline Evento & $\begin{array}{c}\Delta Q \text { Tobin } \\
(\%) \text { por ano }\end{array}$ & 2007 & 2008 & 2009 & 2010 & 2011 & $2007 / 11$ \\
\hline Entrada no ISE & $\Delta Q>0$ & 6 & 1 & 8 & - & 1 & 16 \\
& $\Delta Q<0$ & 1 & 5 & - & - & 2 & 8 \\
& Total & 7 & 6 & 8 & - & 3 & 24 \\
\hline Saída do ISE & $\Delta Q>0$ & 2 & - & - & - & - & 2 \\
& $\Delta Q<0$ & 3 & 5 & 1 & - & 2 & 11 \\
& Total & 5 & 5 & 1 & - & 2 & 13 \\
\hline
\end{tabular}

Fonte: Dados da pesquisa.

\subsection{Determinantes de adesão ao ISE}

A seguir são apresentados os resultados da regressão logit para os dados, com o objetivo de identificar os determinantes da adesão ao ISE.

Na Tabela 6 apresentam-se os resultados da regressão, para os métodos do tipo pooled e de dados em painel, para efeitos fixos e aleatórios.

Tabela 6

Determinantes de adesão ao ISE

\begin{tabular}{|c|c|c|c|c|}
\hline Coeficiente-variável & Logit Pooled & $\begin{array}{c}\text { Logit } \\
\text { efeito eixo }\end{array}$ & $\begin{array}{c}\text { Logit } \\
\text { efeito aleatório }\end{array}$ & $d y / d x$ \\
\hline$\beta_{0}-$ Intercepto & $-7,31 * * *$ & - & $-19,049 * * *$ & \\
\hline$\beta_{1}-L n A t$ & $0,373 * * *$ & $1,225 * *$ & $0,983 * *$ & $0,983 * *$ \\
\hline$\beta_{2}-R O A$ & $0,042 * *$ & $0,163 * *$ & $0,148 * *$ & $0,149 * *$ \\
\hline$\beta_{3}-$ Setor (Altoimpacto $)$ & $0,72 * * *$ & - & $1,38 *$ & $1,385^{*}$ \\
\hline$\beta_{4}-\operatorname{Crise}(2008) * R O A$ & & $-0,09 *$ & $-0,08 *$ & $-0,086^{*}$ \\
\hline $\mathrm{N}$ & 441 & 441 & 441 & \\
\hline Hosmer Lemeshow (Prob > chi2) & 0,36 & - & & \\
\hline LR Test $($ Prob $>$ chi 2$)$ & & 0 & - & \\
\hline Wald Test (Prob > chi2) & 0 & - & 0 & \\
\hline Pseudo $R^{2}$ & 0,07 & - & - & \\
\hline LM Test Breush-Pagan (Prob > chi2) & & & 0 & \\
\hline Hausman Test (Prob $>$ chi2) & & & 0,8861 & \\
\hline
\end{tabular}

O modelo logit na forma pooled foi considerado inadequado para a obtenção dos parâmetros, devido à rejeição da hipótese nula do teste de LM de Breush-Pagan, e aponta para a estimação do modelo via dados em painel. Já a não rejeição da hipótese nula do teste de Hausman indica que não existe relação entre a heterogeneidade não observada $\left(u_{i t}\right)$ e os regressores e que, por isso, o modelo de efeitos aleatórios é considerado o mais adequado, quando comparado com o modelo de efeitos fixos. Assim, focou-se na análise do modelo estimado via efeitos aleatórios, o qual procedeu-se a análise de sensibilidade $(d y / d x)$. Com relação ao teste de 
Hosmer-Lemeshow, verificou-se a não rejeição da hipótese nula, resultado que confirma o bom ajuste do modelo (Prob $>$ chi2 $=0,36)$.

O tamanho da empresa ( $L n A t$ ) é uma variável analisada em um elevado número de trabalhos e os resultados estimados evidenciaram relação positiva $\left(\beta_{1}=0,983\right)$ com a probabilidade de a empresa estar listada no ISE. O resultado está coerente com o sinal encontrado por Nunes et al. (2010), Artiach et al. (2010) e Andrade et al. (2012), e corrobora os argumentos de que empresas maiores estão expostas a uma pressão das diferentes demandas dos stakeholders de uma empresa. A análise de sensibilidade aponta que uma variação de $10 \%$ em LnAt aumenta em 9,83\% a probabilidade de adesão ao ISE.

Já com relação à variável rentabilidade, identificou-se que a rentabilidade sobre o ativo $(R O A)$ foi significativa e seu sinal mostra uma associação positiva $\left(\beta_{2}=0,148\right)$ com a probabilidade de a empresa estar listada no ISE. A análise de sensibilidade mostra que um aumento de $10 \%$ na variável $R O A$ aumenta em $1,49 \%$ a probabilidade de sua adesão ao ISE. No entanto, se, por um lado, empresas com maiores ROAs tendem a apresentar relação positiva com a probabilidade de adesão ao ISE, em linha com o triple bottom line, por outro, em um período de crise financeira, como o ano de 2008, a relação tende a ser negativa. Este resultado é apresentado pela variável de interação Crise $2008 * R O A$. Embora o parâmetro tenha apresentado baixa magnitude $\left(\beta_{4}=-0,08\right)$, o seu sinal sugere que, no ano de 2008, as empresas tiveram dificuldades em implementar projetos de sustentabilidade empresarial, ou, então, que a performance social e ambiental de tais empresas não foi compensada, em termos econômicos, o que contraria a lógica do triple bottom line.

Já a análise do setor de atividade mostra que a probabilidade de adesão ao ISE para as empresas brasileiras é afetada pelas características do setor em que está inserida. O resultado mostrou $\left(\beta_{3}=1,38\right)$ que os setores classificados como de maior impacto ambiental têm maiores chances de adesão ao ISE. A análise de sensibilidade permite identificar que o setor de atuação da empresa é um determinante de adesão ao ISE. Este resultado é coerente com aqueles encontrados por Nunes et al. (2010) para o mercado brasileiro.

As variáveis oportunidades de investimento, capacidade de financiamento, endividamento e crescimento da receita não foram significativas nos modelos estimados e, por isso, tiveram os seus valores suprimidos na Tabela 6. Embora não significativas, a inclusão destas variáveis contribui 
com a literatura nacional que busca identificar os possíveis fatores que influenciam a adesão de uma empresa ao ISE, especialmente em avaliar a possível influência de fatores macroeconômicos, como a crise financeira de 2008.

\subsection{Relação entre adesão ao ISE e valor de mercado da empresa}

Para verificar a relação entre sustentabilidade empresarial e valor de mercado das empresas, foi utilizado o método de estimação de dados em painel. A consistência dos resultados, testados para diferentes métricas relacionadas ao valor e desempenho das ações no mercado, permitiu maior robustez à análise dos dados.

Na Tabela 7 apresentam-se os resultados e os testes de especificação do modelo. Verificou-se que, em todas as regressões, o teste de BreushPagan rejeitou a hipótese nula de que não há diferenças entre os estimadores pelo método $\mathrm{MQO}($ Pooled $)$ e dados em painel, e indica que há heterogeneidade não observada entre as empresas e no tempo. E, neste caso, os estimadores por MQO são considerados viesados e inconsistentes. Os testes apresentados apontam que a hipótese de homocedasticidade foi rejeitada, a $5 \%$, nos três modelos. Já com relação à hipótese de não correlação serial dos resíduos, ela não foi rejeitada apenas para a variável $Q$ de Tobin, mas também para as variáveis valor de mercado e market to book. Por isso, em todas as regressões, recorreu-se ao método robusto de estimação. O mesmo procedimento foi utilizado por Freguete \& Funchal (2012).

Após a aplicação do teste de hausman para as regressões, identificou-se que a presença de heterogeneidade não observada está correlacionada com os regressores nas regressões em que as variáveis explicadas foram o valor de mercado e market to book, o que sugere que o modelo de efeitos fixos é mais adequado nestas condições. Por outro lado, para a variável $Q$ de Tobin, o resultado do teste de hausman não rejeitou a hipótese de que a heterogeneidade não observada não assume correlação com os regressores e, por isso, o modelo de efeitos aleatórios é considerado o mais adequado. Embora com tais diferenças, os resultados são considerados robustos.

Com relação à análise dos coeficientes, especialmente o da variável de maior interesse (ISE), foram encontradas novas evidências no mercado brasileiro. 
O parâmetro B1, referente à variável ISE, indica que, em período de não crise financeira, a sua relação com as métricas de valor, embora com sinal positivo em todas as regressões, é considerada nula, assim como encontrado por Freguete \& Funchal (2012). Já Rossi:2009 encontrou uma relação significativa e positiva entre ISE e $Q$ de Tobin. A diferença no critério de amostragem definido pelos autores pode ter sido a causa da divergência na significância da relação.

Com relação a $B_{2}$ (crise 2008 ), identificou-se que, para as empresas não listadas no ISE, a relação foi significativa e negativa com as três métricas de valor, em coerência com os resultados apresentados por Freguete \& Funchal (2012). Este resultado confirma a desvalorização das ações no mercado brasileiro no ano de 2008, conforme esperado. No entanto, o parâmetro $B_{3}(I S E *$ Crise 2008$)$ indica relação positiva com as três métricas de valor para as variáveis $Q$ de Tobin $(0,127)$, valor de mercado $(0,248)$ e market to book $(0,102)$, sendo a relação significativa confirmada apenas para as duas primeiras. A relação positiva indica que empresas que adotaram estratégias de sustentabilidade empresarial foram mais valorizadas no ano da crise financeira de 2008. Embora o sinal positivo também tenha sido encontrado por Freguete \& Funchal (2012), estes autores não encontraram relação significativa entre ISE e métricas de valor, no ano de 2008.

Com relação ao parâmetro $B_{4}$ (ISE $*$ PosCrise), verificou-se uma inversão do sinal entre empresas listadas no ISE, no período de 2009 a 2011, tornando-se negativa com as três métricas de valor testadas. Embora a relação tenha sido significativa apenas para a variável market to book, o seu sinal negativo sugere uma pior performance das ações de empresas listadas no ISE, no período pós-crise financeira. 
Tabela 7

Relação entre ISE e métricas de valor de mercado

\begin{tabular}{|c|c|c|c|c|c|c|}
\hline \multirow{2}{*}{$\begin{array}{l}\text { Coeficiente } \\
\text { Variável }\end{array}$} & \multicolumn{2}{|c|}{$Q$ Tobin } & \multicolumn{2}{|c|}{ Valor de mercado } & \multicolumn{2}{|c|}{ Market to book } \\
\hline & Fixos & Aleatórios & Fixos & Aleatórios & Fixos & Aleatórios \\
\hline$\beta_{0}-$ Intercepto & $5,76 * * *$ & $5,05 * * *$ & $15,244 * * *$ & $12,597 * * *$ & $7,600 * * *$ & $5,194 * * *$ \\
\hline$\beta_{1}-I S E$ & 0,008 & 0,015 & 0,051 & 0,073 & 0,102 & 0,126 \\
\hline$\beta_{2}-$ Crise 2008 & $-0,296^{* * *}$ & $-0,296 * * *$ & $-0,632 * * *$ & $-0,610 * * *$ & $-0,452 * * *$ & $-0,428 * * *$ \\
\hline$\beta_{3}-I S E *$ Crise 2008 & $0,136^{*}$ & $0,127 *$ & $0,248^{*}$ & $0,192 *$ & 0,165 & 0,124 \\
\hline$\beta_{4}-I S E *$ PosCrise & $-0,035$ & $-0,045$ & $-0,06$ & $-0,108$ & $-0,147 * * *$ & $-0,187 * *$ \\
\hline$\beta_{5}-L n A t$ & $-0,295 * * *$ & $-0,244 * * *$ & $-0,618 * * *$ & $-0,449 * * *$ & $-0,389 * * *$ & $-0,244 * * *$ \\
\hline$\beta_{6}-R O A$ & $0,014 * * *$ & $0,017 * * *$ & $0,034 * * *$ & $0,038 * * *$ & $0,019 *$ & $0,026^{* *}$ \\
\hline$\beta_{7}-\ln \operatorname{Div} B r A T$ & $-0,192 * * *$ & $-0,174 * * *$ & $-0,308 * * *$ & $-0,250 * * *$ & $-0,172 * *$ & $-0,123 * *$ \\
\hline$\beta_{8}-$ Setor & - & $1 ; 2 ; 13$ & - & $1 ; 2 ; 13 ; 15$ & - & $1 ; 2 ; 11 ; 12$ \\
\hline$N$ & 410 & 410 & 424 & 424 & 409 & 409 \\
\hline $\mathrm{N}^{\circ}$ de grupos & 81 & 81 & 81 & 81 & 81 & 81 \\
\hline Wald Test (Prob > chi2) & 0 & 0 & 0 & 0 & 0 & 0 \\
\hline $\begin{array}{l}\text { LM Test Breush-Pagan } \\
(\text { Prob }>\text { chi2) }\end{array}$ & \multicolumn{2}{|c|}{$\overline{0}$} & \multicolumn{2}{|c|}{0} & \multicolumn{2}{|c|}{0} \\
\hline Hausman test & \multicolumn{2}{|c|}{0,1232} & \multicolumn{2}{|c|}{0} & \multicolumn{2}{|c|}{0,0005} \\
\hline Autocorrelação serial & \multicolumn{2}{|c|}{0,1511} & \multicolumn{2}{|c|}{0,0008} & \multicolumn{2}{|c|}{0,0002} \\
\hline Heterocedasticidade & \multicolumn{2}{|c|}{0} & \multicolumn{2}{|c|}{0} & \multicolumn{2}{|c|}{0} \\
\hline \multicolumn{7}{|c|}{$\begin{array}{l}\text { Fonte: Dados da pesquisa. } \\
(* * *) \text { Significativo, a } 1 \% \text {; (**) Significativo, a } 5 \% \text {; (*) Significativo, a } 10 \% \text {. } \\
\text { A variável } Q \text { de Tobin foi transformada em logaritmo natural. Procedimento semelhante foi ado- } \\
\text { tado por Rossi Junior (2009). Já a variável valor de mercado foi dividida pelo ativo total da em- } \\
\text { presa. }\end{array}$} \\
\hline
\end{tabular}

Com relação às variáveis de controle, elas apresentaram-se consistentes e com sinais coerentes com o que foi encontrado na literatura. A variável tamanho ( $L n A t)$ da empresa apresentou relação negativa e significativa na maioria das regressões e está coerente com o que foi identificado por Rossi Junior (2009), para o mercado brasileiro, resultado que também está coerente com o trabalho de Lo \& Sheu (2007). As variáveis ROA e endividamento bruto sobre o ativo total $(\ln D i v B r A T)$ apresentaram sinais significantes, positivo e negativo, respectivamente. Estas evidências apontam que investidores tendem a valorizar uma adequada gestão dos ativos em gerar lucros, e empresas com maiores níveis de endividamento tenderam a ser menos valorizadas. Resultados semelhantes foram encontrados por Rossi Junior (2009) e por Freguete \& Funchal (2012).

\section{Conclusões}

Este artigo foi realizado com o objetivo de identificar variáveis que influenciam a adesão ao ISE e sua relação com as métricas de valor e de performance das ações das empresas brasileiras de capital aberto. O modelo empírico especificado para determinar a adesão ao ISE levou em conta um 
conjunto de variáveis relacionadas com as empresas, tais como tamanho, rentabilidade, endividamento, capacidade de financiamento, crescimento da receita e setor de atuação, e considerou um período que permitiu analisar se a crise financeira de 2008 afetou a adesão das empresas no ISE e a relação com as métricas de valor e de performance das ações.

Ao dividir as empresas em listadas e não listadas no ISE, a análise de comparação de médias permitiu verificar que, para todo o período amostral, as empresas listadas têm menor valor de mercado, maior rentabilidade, maior capacidade de financiamento, maior tamanho, menor endividamento de curto prazo e menor crescimento da receita. Apenas não foi identificada a diferença de médias para o endividamento total.

Com relação aos possíveis determinantes, identificou-se que o tamanho da empresa e o nível de impacto ambiental que está inerente ao seu setor de atividade são as principais variáveis que afetaram a adesão ao ISE. A rentabilidade e sua interação com a crise financeira de 2008 também exerceram influência, porém, afetaram de forma negativa a probabilidade de adesão ao ISE. No que diz respeito à relação entre ISE e as métricas de valor, concluiu-se que o período de crise financeira de 2008 alterou de modo significativo a dinâmica da relação entre a SE e as métricas de valor. A hipótese de que existe relação positiva entre SE e valor não foi rejeitada em períodos que antecederam o ano da crise financeira, como foi encontrado por Rossi Junior (2009). No ano de 2008, os indícios de relação positiva corroboram os argumentos apresentados por Mcguire et al. (1988), porém, os resultados sugerem que, no período pós-crise, o valor de mercado das empresas listadas apresentou uma pior performance, quando comparado com o valor das ações de empresas não listadas no ISE, corroborando os argumentos de Yelkikalan \& Köse (2012) de que os efeitos de uma crise financeira no mercado sobre as práticas de responsabilidade social e ambiental podem acontecer em diferentes direções.

Como limitação do trabalho, cabe destacar a não utilização de outras proxies para a sustentabilidade empresarial, a fim de avaliar a robustez dos resultados a partir de diferentes métricas das práticas de SE. Para futuras pesquisas, recomenda-se que seja explorada a relação entre SE e valor da empresa, visando identificar como a decisão de investir em sustentabilidade empresarial é afetada por fatores macroeconômicos, políticos e sociais. 


\section{Referências}

Alexander, Gordon J., \& Buchholz, Rogene A. 1978. Corporate Social Responsibility and Stock Market Performance. Academy Of Management Journal, 3, 479-485.

Andrade, Lélis P., Moreira, Bruno C. M., \& Pedrosa, Guilherme H. 2012. Determinantes Da Performance de Sustentabilidade Empresarial: Uma Nova Análise Sobre as Empresas Brasileiras de Capital Aberto. XXXVI ENANPAD. Rio de Janeiro.

Artiach, Tracy, Lee, Darren, Nelson, David, \& Walker, Julie. 2010. The Determinants of Corporate Sustainability Performance. Accounting Finance, 1, 31-51.

Aupperle, Kenneth E., Carroll, Archie B., \& Hatfield, John D. 1985. An Empirical Examination of the Relationship Between Corporate Social Responsibility and Profitability. Academy of Management Journal, 28, 446-463.

Barnett, Michael L. 2005. Stakeholder Influence Capacity and the Variability of Financial Returns to Corporate Social Responsibility. Academy of Management Review, Working paper. Available: http://www.ssrn. com/abstract $=853086$. Acesso em 10 de Fevereiro de 2012.

Becchetti, Leonardo, Di Giacomo, Stefania, \& Pinnacchio, Damiano. 2005. Corporate Social Responsibility and Corporate Performance: Evidence from a Panel of U.S. Listed Companies. Working paper, (CEIS). Disponível em: http://dspace.uniroma2.it/dspace/ handle/2108/362. Acesso em: 06 de fevereiro de 2013.

Boaventura, João M. G., Cardoso, Fernando R., Silva, Edison S. Da, \& Silva, Ralph S. 2009. Teoria Dos Stake-Holders e Teoria Da Firma: Estudo Sobre a Hierarquização Da Função-Objetivo Em Empresas. Revista Brasileira de Gestão de Negócios, 11, 289-307.

Boaventura, João M. G., Silva, Ralph S., Mello, Rodrigo B. de, \& Santos, Humberto M. 2012. Pesquisa Empírica Da Relação Entre a Performance Corporativa Social e a Performance Corporativa Financeira - CSP/CFP: O Viés Da Formação Do Pesquisador. Encontro Brasileiro de Finanças, São Paulo, SP. 
Bolsa de Mercadorias e Valores de São Paulo (BM\&FBOVESPA). 2012. Disponível em: http://www.bmfbovespa.com.br/home. aspx?idioma=pt-br. Acesso em: 30 jan. 2013.

Borba, Paulo R. F. 2005. Relação Entre Desempenho Social Corporativo e Desempenho Financeiro de Empresas No Brasil. Dissertação de Mestrado em administração. Faculdade de Economia, Administração e Contabilidade da Universidade de São Paulo - FEA-USP.

Brito, Bruno M. B. 2005. A Reação Do Mercado Acionário a Eventos Ambientais. Dissertação (Mestrado em Administração) - Instituto COPPEAD de Administração, Universidade Federal do Rio de Janeiro, Rio de Janeiro.

Caldelli, Andrea, \& Pamigiani, Marisa L. 2004. Management Information System - A Tool for Corporate Susteinability. Journal of Business Ethics, 55.

Cameron, Adrian C., \& Trivedi, Pravin K. 2010. Microeconometrics Using Stata. Texas: Stata Press.

Campbell, Andrew. 1997. Stakeholders: The Case in Favour. Long Range Planning, 30, 446-450.

Carroll, Archie B. 1979. A Three-Dimensional Conceptual Model of Corporate Performance. Academy of Management Review, 4, 497-505.

Cavalcante, Luiz R. M. T., Bruni, Alexandre L., \& Costa, Fábio J. M. 2007. Sustentabilidade Empresarial e Desempenho Corporativo: Uma Análise Do Mercado Brasileiro de Ações. Proceedings of the XXXI Encontro ANPAD, Rio de Janeiro, Brasil.

Cavalcante, Luiz R. M. T., Bruni, Alexandre L., \& Costa, Fábio J. M. 2009. Sustentabilidade Empresarial e Valor Das Ações: Uma Análise Na Bolsa de Valores de São Paulo. Revista de Gestão Social e Ambiental - RGSA, 3, 70-86.

Chung, Kee H., \& Pruitt, Stephen W. 1994. A Simple Approximation of Tobin's. Financial Management, 23, 70-74.

Clarkson, Peter, Yue, Li, Richardson, Gordon D., \& Vasvari, Florin P. 2006. Does It Really Pay to Be Green? Determinants and Consequences 
of Proactive Environmental Strategies. Working paper. Disponível em: http://papers.ssrn.com/sol3/papers.cfm?abstract_id= 1655969. Acesso em 06 de março de 2013.

Coase, Ronald H. 1937. The Nature of the Firm. Economica, 4, 386-405.

Cochran, Philip L., \& Wood, Robert A. 1984. Corporate Social Responsibility and Financial Performance. Academy of Management Journal, 27, $42-56$.

Donaldson, Thomas, \& Preston, Lee E. 1995. The Stakeholder Theory of the Corporation: Concepts, Evidence and Implications. Academy of Management Review, 20, 65-91.

Elkington, John. 1998. Cannibals with Forks. Gabriola Island: New Society Publishers.

Evan, Willian M., \& Freeman, Robert E. 1993. A Stakeholder Theory of the Modern Corporation: Kantian Capitalism. In: Donaldson, T., \& Werhane, P. H. (eds), Ethical Issues in Business. Englewood Cliffs: Prentice-Hall.

Famá, Rubens, \& Barros, Lucas A. B. C. 2000. Q de Tobin e Seu Uso Em Finanças: Aspectos Metodológicos e Conceituais. Caderno de Pesquisas em Administração, 7.

Federação Brasileira de Bancos (FEBRABAN). 2013. Disponível em: http://www.febraban.org.br/Febraban.asp?id_pagina= 1010. Acesso em 30/01/2013.

Freeman, Robert E. 1984. Strategic Management: A Stakeholder Approach. Boston: Pitman.

Freguete, Lilian M., \& Funchal, Bruno. 2012. A Prática de Responsabilidade Social Corporativa e O Desempenho Financeiro de Empresas Em Épocas de Crise. Associação Nacional dos Programas de PósGraduação em Ciências Contábeis (ANPCONT), 6, 2012, Florianópolis (SC). Anais.

Friedman, Milton. 1970. The Social Responsibility of Business is Increase its Profits. New York Magazine, 33, 122-126.

210 Rev. Bras. Finanças (Online), Rio de Janeiro, Vol. 11, No. 2, June 2013 
Jensen, Michael. 2001. Value Maximization, Stakeholder Theory, and the Corporate Objective Function. Journal of Applied Corporate Finance, 14, 8-21.

Lee, Darren. 2006. An Analysis of the Sustainability Investment Strategy Employing the Dow Jones World Sustainability Index. Tese de doutorado, Monash University, Clayton.

Liu, Chunyan, Uchilda, Konari, \& Yufeng, Yang. 2010. Corporate Governance and Firm Value During the Global Financial Crisis: Evidence from China. Disponível em http://ssrn.com/abstract=1693087. Acesso em 30 setembro de 2012.

Lo, Shih-Fang, \& Sheu, Her-Jiun. 2007. Is Corporate Sustainability a Value-Increasing Strategy for Business? Corporate Governance: An International Review, 15, 345-357.

Machado Filho, Claudio A. P., \& Zylbersztajn, Decio. 2004. A Empresa Socialmente Responsável: O Debate e as Implicações. Revista de Administração, 3, 242-254.

Marom, Isaiah Y. 2006. Toward a Unified Theory of the CSP-CFP Link. Journal of Business Ethics, 67, 191-200.

Mattos, Adriana. 2007. Brasil É Destaque Nos Princípios Do Equador. Valor Econômico. São Paulo: 25/04/2007. Disponível em: http://www2. senado.gov.br/bdsf/item/id/76691. Acesso em: 29/01/2013.

Mcguire, Jean B., Sundgren, Alison, \& Schneeweis, Thomas. 1988. Corporate Social Responsibility and Firm Financial Performance. Academy of Management Journal, 31, 854-872.

McWilliams, Abagail, \& Siegel, Donald. 2000. Corporate Social Responsibility and Financial Performance: Correlation or Misspecification? Academy of Management Review, 21, 603-609.

Myers, Stewart C., \& Majluf, Nicholas S. 1984. Corporate Financing and Investment Decisions When Firms Have Information Investors Do Not Have. Journal of Financial Economics, 13, 187-221. 
Nossa, Valcemiro, C., Figueira Jesuína, Silva Junior, Annor Da, Silva Baptista, Ézio C., \& Neris Nossa, Silvania. 2009. A Relação Entre O Retorno Anormal e a Responsabilidade Social e Ambiental: Um Estudo Empírico Na Bovespa No Período de 1999 a 2006. BBR Brazilian Business Review, 6, 121-136.

Nunes, Julyana G., Teixeira, Aridelmo J. C., Nossa, Valcemiro, \& Galdi, Fernando C. 2010. Análise Das Variáveis Que Influenciam a Adesão Das Empresas Ao Índice BM\&F Bovespa de Sustentabilidade Empresarial. BASE - Revista de Administração e Contabilidade da Unisinos, 7, 328340 .

Pava, Moses L., \& Krausz, Joshua. 1996. The Association Between Corporate Social-Responsibility and Financial Performance: The Paradox of Social Cost. Journal of Business Ethics, 15, 321-357.

Perera, Luiz C. J., Gonçalves, Ronaldo, Antunes, Maria T. P., \& Imoniana, Joshua O. 2011. Sustainable Practice and Business Profitability in Brazil. Journal of International Business and Economics, 11, 14-24.

Rajan, Raghuram G., \& Luigi, Zingales. 1998. Which Capitalism? Lessons from the East Asian Crisis. Journal of Applied Corporate Finance, 11, $40-48$.

Reed, Donald J. 2001. Stalking the Elusive Business Case for Corporate Sustainability. Washington: World Resources Institute. Disponível em: http://www.greenbiz.com/sites/default/ files/document/016F24459.pdf. Acesso em: 30/01/2013.

Rossi Junior, José L. 2009. What is the Value of Corporate Social Responsibility? An Answer from the Brazilian Sustainability Index. Disponível em: http://papers.ssrn.com/sol3/papers.cfm?abstract_id= 1338114. Acesso em 06 de novembro de 2012.

Souto, Belén F. F. 2009. Crisis and Corporate Social Responsibility: Threat or Opportunity? International Journal of Economic Sciences and Applied Research, 2, 36-50.

Sundaran, Anant K., \& Inkpen, Andrew C. 2004. The Corporate Objective Revisited. Organization Science, 15, 350-364. 
Teixeira, Evimael A., Nossa, Valcemiro, \& Funchal, Bruno. 2011. O Índice de Sustentabilidade Empresarial (ISE) e Os Impactos No Endividamento e Na Percepção de Risco. Revista de contabilidade e finanças [online], 22, 29-44.

Ullmann, Arieh A. 1985. Data in Search of a Theory: A Critical Examination of the Relationships Among Social Performance, Social Disclosure, and Economic Performance of U.S. Firms. Academy of Management Review, 10, 540-557.

Van Marrewijk, Marcel. 2003. Concepts and Definitions of CSR and Corporate Sustainability: Between Agency and Communion. Journal of Business Ethics, 44, 95-105.

Waddock, Sandra A., \& Graves, Samuel B. 1997. The Corporate Social Performance - Financial Performance Link. Strategic Management Journal, 18, 303-319.

Wajnberg, Daniel, \& Lemme, Celso F. 2009. Exame Da Divulgação Do Relacionamento Entre Iniciativas Socioambientais e Desempenho Financeiro Corporativo Nos Bancos Brasileiros. Revista de Gestão Social e Ambiental - RGSA, 3, 53-69.

Yelkikalan, Nazan, \& Köse, Can. 2012. The Effects of the Financial Crisis on Corporate Social Responsibility. International Journal of Business and Social Science, 3, 292-300. 